\title{
Estudo morfológico de fígado de bovinos abatidos em frigoríficos industriais sob inspeção estadual no Oeste e no Planalto de Santa Catarina, Brasil
}

\author{
Morphologic study of bovine livers slaughtered in industrial slaughterhouse under State Inspection \\ Service in West and Highland regions of Santa Catarina, Brazil
}

\author{
Ricardo Evandro Mendes $^{{ }^{*}}$ Célso PilatiI
}

\section{RESUMO}

Os critérios para condenação e liberação de órgãos submetidos ao serviço oficial de inspeção de carnes têm sido controversos. Argumenta-se que órgãos que não apresentam lesões macroscópicas visíveis podem ainda assim apresentar alterações microscópicas; por outro lado, órgãos rejeitados durante exame macroscópico podem revelar-se normais ao exame histológico. Um estudo morfológico, macroscópico e microscópico foi conduzido em fígados de bovinos durante a inspeção de rotina em frigoríficos comerciais. Os fígados de bovinos foram divididos em dois grupos: condenados e não-condenados, de acordo com os padrões de Serviço de Inspeção Animal do Estado de Santa Catarina (SIE). Fragmentos de fígados foram fixados em formol neutro a $10 \%$ e processados rotineiramente para exame histológico. Os objetivos foram estabelecer as principais razões para a condenação de fígados bovinos na rotina de inspeção de carnes do SIE, avaliar os fígados de ambos os grupos por exame histológico e estabelecer possíveis etiologias associadas às lesões que levaram à condenação. De acordo com o SIE, as razões para condenação foram: telangiectasia $(32,2 \%)$, fasciolose $(18,5 \%)$, abscessos (18,0\%), manchas claras e irregulares (12,6\%), aderências entre fígado e diafragma (6,0\%), fígado amarelo e friável (4,2\%), pontos claros ou escuros $(3,6 \%)$, nódulos $(1,8 \%)$ e outras causas (3,0\%). No exame microscópico, os fígados do grupo condenado mostraram telangiectasia (25,7\%), abscessos (18,0\%), fasciolose $(16,1 \%)$, fibrose capsular (13,2\%), necrose aleatória (8,4\%), degeneração (3,6\%), infiltrado inflamatório (2,4\%), neoplasia (1,8\%), ausência de alterações $(7,2 \%)$ e alterações variadas (3,6\%). Dentre os fígados do grupo de não-condenados, 73,0\% não tinham alterações macroscópicas; no entanto, observouse infiltrado inflamatório (12,6\%), necrose aleatória $(7,8 \%)$, telangiectasia $(4,8 \%)$, fasciolose $(0,6 \%)$ e alterações variadas (1,2\%). Conclui-se que existem incongruências na rotina de inspeção de carnes do SIE, uma vez que as alterações microscópicas observadas em $27 \%$ dos fígados nãocondenados não foram detectadas pelo exame macroscópico e, assim, órgãos com lesão são liberados para consumo humano. Por outro lado, vários fígados do grupo condenado foram rejeitados de forma desnecessária, causando perdas econômicas importantes.

Palavras-chave: fígado, histopatologia, inspeção, bovino.

\section{ABSTRACT}

Criteria for condemnation and liberation of organs submitted to the official meat inspection services have been controversial, it is argued that organs witch do not present gross lesions may still have certain degree of pathological changes under microscopic scrutiny; conversely, organs rejected on microscopic exam may reveal normalcy under histological evaluation. A gross and histological morphologic study was conducted in bovine livers during meat inspection in commercial slaughter; bovine livers were allotted in two groups: condemned and non-condemned, according to the Animal Standard Meat Inspection (SIS) of the State of Santa Catarina, Brazil. Liver fragments were fixed in $10 \%$ neutral formalin and processed for routine histopathological examination. The objectives were: to establish the main reasons for condemnation of bovine livers in the meat inspection routine of SIS, to evaluate livers from both groups by histological examination and to identify the possible etiologies responsible for condemnation. According to the SIS, the reasons for condemnation were: telangiectasis (32.2\%), fasciolosis (18.5\%), abscesses (18.0\%), irregular and bright spots (12.6\%), adherence between liver and diaphragm (6.0\%), yellow and friable liver (4.2\%), dark or pale spots (3.6\%), nodules $(1.8 \%)$ and other causes $(3.0 \%)$. Under microscopic study livers from condemned group showed telangiectasis (25.7\%), abscesses (18.0\%), fasciolosis (16.1\%), capsular fibrosis (13.2\%), random necrosis (8.4\%), degeneration (3.6\%), inflammatory infiltrate (2.4\%), neoplasia

'Universidad de Córdoba (UCO), Campus Universitario de Rabanales, Edificio de Sanidad Animal, Departamento de Anatomía y Anatomía Patológicas Comparadas. Ctra. Madrid-Cádiz, s/n. 14014, Córdoba, España. E-mail: z62memer@uco.es. *Autor para correspondência.

IUniversidade do Estado de Santa Catarina (UDESC/CAV), Laboratório de Patologia Animal. Av. Luiz de Camões, 2090, CP 281, 88520-000, Lages, SC, Brasil. 
(1.8\%), no changes (7.2\%) and miscellaneous changes (3.6\%). Among livers from the non condemned group, $73 \%$ did not have microscopic changes; however, inflammatory infiltration (12.6\%), necrosis (7.8\%), telangiectasis (4.8\%), fasciolosis $(0.6 \%)$ and miscellaneous lesions (1.2\%) were detected in the remaining $27 \%$. In conclusion, inaccuracy was detected in the meat inspection routine of SIS since the microscopic changes observed in $27 \%$ of the non-condemned livers were not detected on gross examination and so affected organs were liberated for human consumption. Conversely several livers among the condemned groups were unnecessarily rejected, consequently causing importantly economic losses.

Key words: liver, histopathology, meat inspection, cattle.

\section{INTRODUÇÃO}

A condenação de órgãos, vísceras e carcaças de animais destinados ao abate pelo serviço de inspeção veterinário é importante para a saúde pública, pois muitas das alterações patológicas são devidas a zoonoses. Portanto, tal prática tem o objetivo de tornar seguro o consumo humano dos alimentos inspecionados (HERENDA et al., 1994).

ALBERTON (2000) cita estudos desenvolvidos em diversos países, os quais demonstraram que a falta de acurácia na linha de inspeção tem elevado os custos de produção dos frigoríficos. De acordo com FREITAS (1999), uma grande dificuldade enfrentada pelos inspetores oficiais em estabelecimentos de abate tem sido relacionada à segurança em diagnosticar as diversas enfermidades e, em seguida, estabelecer o destino apropriado e confiável para as carcaças e vísceras desses animais.

Dentre as afecções mais freqüentes do fígado, estão: telangiectasia, hepatite, peri-hepatite, fasciolose, hidatidose e tuberculose (WILSON, 1970; SANTOS, 1986; HERENDA et al., 1994). Em um estudo realizado no Estado do Rio de Janeiro (MELLO, 2000), foi encontrada, uma taxa de condenação de fígados de 4,73\% pelo SIF (Sistema de Inspeção Federal); e de 6,74\% pelo SIE (Sistema de Inspeção Estadual). As causas e freqüências de condenação de fígados encontradas pelo SIF foram as seguintes: telangiectasia - 40,0\%, abscesso - 24,3\%, fasciolose - 20,5\%, perihepatite - 9,0\%, congestão - 2,6\% e causas diversas $1,2 \%$. Já as estabelecidas pelo SIE foram: abscesso $45,0 \%$, telangiectasia - 42,2\%, peri-hepatite - 10,1\%, hidatidose - $1,8 \%$ e tuberculose - $0,9 \%$. Segundo dados de Moreira et al. (1999), a taxa de condenação de fígados em abatedouro varia entre 3,46 e 21,12\%.

Os resultados do trabalho realizado por NEVES (1985) revelaram a existência de alta possibilidade de erro durante a inspeção post-mortem. $\mathrm{Na}$ literatura, são encontrados poucos trabalhos científicos sobre a condenação de órgãos de bovinos pelo serviço de inspeção. Com este trabalho, pretendese iniciar o preenchimento dessa lacuna e fornecer subsídios aos inspetores para um trabalho mais acurado. Este estudo teve, portanto, como objetivos verificar a ocorrência e as causas de condenação de fígados de bovinos em dois frigoríficos sob regime de Inspeção Estadual no Estado de Santa Catarina, avaliar, por meio do exame microscópico, os fígados condenados e não condenados pelo SIE, e, finalmente, identificar possíveis causas para as condenações daqueles fígados.

\section{MATERIAL E MÉTODOS}

As amostras foram coletadas em dois frigoríficos sob inspeção do SIE catarinense, localizados na região do Planalto Serrano e no Alto Vale do Itajaí. Durante a pesquisa, os proprietários ou os transportadores dos animais foram questionados a respeito do regime de criação dos bovinos, de sua origem, raça, idade, etc.

Utilizou-se a fórmula abaixo para estabelecer o número total da amostragem (MENDENHALL \& BEAVER, 1990; SAMPAIO, 2002), com um intervalo de confiança de $95 \%$ e uma margem de erro de 5\%. A freqüência esperada dos fígados condenados foi obtida no decorrer da coleta do material, ou seja, os dados de condenação observados nos frigoríficos onde foram realizadas as coletas serviram para determinar o índice de condenação.

$$
\mathrm{N}=\frac{\mathrm{z}^{2} \cdot \mathrm{p} \cdot \mathrm{q}}{\mathrm{e}^{2}}
$$

Em que:

$\mathrm{N}$ = número da amostra a ser testada;

$\mathrm{p}$ = freqüência esperada;

$\mathrm{q}=1-\mathrm{p}$;

$\mathrm{z}$ = grau de confiança $(1,96)$;

$\mathrm{e}=$ erro padrão.

A amostra é constituída por 334 fragmentos de fígados. Esses foram divididos em dois grupos, G1 (órgãos condenados pelo SIE) e G2 (órgãos liberados pelo SIE), contendo 167 amostras cada um. Essas amostras foram provenientes de uma população total de 1.011 bovinos, conforme descrito abaixo, de várias idades, de ambos os sexos e de regime alimentar variado, sendo todos os animais provenientes do Estado de Santa Catarina. Os dias de coletas foram escolhidos aleatoriamente, nunca ultrapassando uma coleta por semana. Os responsáveis pelos estabelecimentos eram avisados somente no final do dia anterior à coleta. 
Fígados inteiros foram selecionados na esteira rolante da linha de abate imediatamente após a abertura da cavidade abdominal e torácica para a remoção das vísceras. Esses foram separados e fotografados para posterior classificação quanto aos aspectos macro e microscópicos. Foi adotado como critério, para compor o G1, a coleta do primeiro fígado condenado pelo inspetor do SIE. Já o segundo era deixado passar e o terceiro era coletado e assim sucessivamente até alcançar o número da amostra total, isto para dispersar ao máximo as coletas. Para o G2, era coletado um fragmento de fígado considerado normal pelo inspetor do SIE, sempre imediatamente após a coleta de um fragmento para o grupo anterior. Os fragmentos de aproximadamente $1 \mathrm{~cm}$ de espessura foram fixados em solução aquosa de formol a $10 \%$ neutro e tamponado. O material coletado foi transportado até o Laboratório de Patologia Animal do Centro de Ciências Agroveterinárias (CAV), da Universidade do Estado de Santa Catarina (UDESC), onde foi realizado o processamento histológico rotineiro para histologia com coloração pela hematoxilina-eosina (HE) e posterior leitura em microscópico óptico.

Utilizou-se estatística descritiva para a apresentação dos principais achados patológicos.

\section{RESULTADOS E DISCUSSÃO}

Os animais utilizados neste estudo eram provenientes de diferentes municípios e mesoregiões do Estado de Santa Catarina. Animais oriundos da região do Planalto Serrano representaram 33\% do total, da região Oeste do estado 29\%, do Planalto Norte 16\%, do Meio-Oeste Catarinense 14\% e do Alto Vale do Itajaí $8 \%$. As demais regiões não foram contempladas nas coletas.

O sistema de alimentação dos bovinos deste estudo era composto em $43 \%$ dos animais por pastagem cultivada (aveia e azevém) e/ou natural, por sistema de semiconfinamento em 54\%, ou seja, com pastagem natural e/ou cultivada e suplementação de grãos diversos. Animais totalmente confinados representaram $3 \%$.

Foi acompanhada a inspeção de 1.011 fígados. Destes, foram condenados pelos inspetores do SIE 321 órgãos, perfazendo uma taxa de condenação de 31,75\%, e coletadas 167 amostras para compor o grupo G1. Do restante dos órgãos liberados ao consumo humano, coletaram-se 167 fragmentos para compor o G2.

A taxa de condenação de fígados observada foi muito superior aos valores encontrados na literatura, variando entre 3,46\% a 21,12\% (MOREIRA et al., 1999; O’SULLIVAN, 1999; MELLO, 2000).
A seguir, são apresentadas as causas de condenações baseadas nas observações macroscópicas dos inspetores do SIE no G1 (Tabela 1) e microscópicas (Tabela 2) encontradas nos dois grupos de estudo.

No G1, do total de amostras coletadas (167), 92,8\% apresentaram alterações microscópicas, sendo o restante representado por fragmentos de fígado sem qualquer tipo de lesão patológica microscópica, mas condenados pelos inspetores do SIE.

A ocorrência macroscópica de abscessos únicos ou múltiplos no G1 foi bastante alta (18,0\%), de acordo com a tabela 1, valor abaixo do encontrado por O’SULLIVAN (1999), 32,6\%, e por MELLO (2000), variando entre $24,3 \%$ e $45 \%$; porém, acima do encontrado por ROBERTS (1982), 11,1\%. A maioria dos abscessos encontrados mostrou-se como focal (73\%), ou seja, apresentavam somente um abscesso, e de tamanho moderado, variando de 2 a 5 centímetros (Figura 1A e B).

Em relação ao sistema de alimentação, 60\% dos abscessos foram observados nos fígados de animais provenientes de confinamento e semiconfinamento e $40 \%$ nos provenientes de alimentação à base de pastagens. Nos órgãos liberados para consumo, não se observou nenhum caso de abscesso na microscopia óptica. Em um lote de onze animais provenientes do município de Lages, em sistema de semiconfinamento e com dieta à base de $1 \%$ de matéria verde e o restante composto por resíduo de cevada, soja e milho, durante 90 dias, a freqüência de abscessos hepáticos foi de 36,36\%, valor bem acima do observado no G1 (18,0\%).

Conforme o artigo 135 do regulamento da inspeção industrial e sanitária de produtos de origem animal do Estado de Santa Catarina, o órgão afetado

Tabela 1 - Número e percentagem das causas de condenação de fígados de bovinos deste estudo após observação macroscópica e classificação pelo inspetor responsável do SIE, Estado de Santa Catarina.

\begin{tabular}{lll}
\hline Causas & $\mathrm{N}^{\mathrm{o}}$ & $\%$ \\
\hline Abscesso & 30 & 18,0 \\
Aderência & 10 & 6,0 \\
Amarelado e friável & 7 & 4,2 \\
Fasciolose & 31 & 18,5 \\
Mancha clara irregular & 21 & 12,6 \\
Telangiectasia & 54 & 32,3 \\
Pontos claros ou escuros & 6 & 3,6 \\
Nódulos & 3 & 1,8 \\
Diversos & 5 & 3,0 \\
Total & 167 & 100 \\
\hline
\end{tabular}


Tabela 2 - Número e percentagem dos achados microscópicos em fígados condenados pelo inspetor responsável (G1) e não condenados (G2) de bovinos abatidos em frigoríficos sob SIE, Estado de Santa Catarina.

\begin{tabular}{|c|c|c|c|c|}
\hline \multirow{2}{*}{ Achados microscópicos } & \multicolumn{2}{|c|}{ G1 } & \multicolumn{2}{|c|}{ G2 } \\
\hline & $\mathrm{N}^{\mathrm{o}}$ & $\%$ & $\mathrm{~N}^{\mathrm{o}}$ & $\%$ \\
\hline Abscesso & 30 & 18,0 & 0 & 0 \\
\hline Degeneração & 6 & 3,6 & 0 & 0 \\
\hline Fasciolose & 27 & 16,1 & 1 & 0,6 \\
\hline Fibrose Capsular & 22 & 13,2 & 0 & 0 \\
\hline Infiltrado inflamatório & 4 & 2,4 & 21 & 12,6 \\
\hline Necrose & 14 & 8,4 & 13 & 7,8 \\
\hline Neoplasia & 3 & 1,8 & 0 & 0 \\
\hline Telangiectasia & 43 & 25,7 & 8 & 4,8 \\
\hline Diversos & 6 & 3,6 & 2 & 1,2 \\
\hline Sem alterações & 12 & 7,2 & 122 & 73,0 \\
\hline Total & 167 & 100 & 167 & 100 \\
\hline
\end{tabular}

pela ocorrência de abscesso pode ser liberado para consumo, após a retirada do mesmo, desde que este seja localizado, circunscrito de pequena extensão e superficial (SANTA CATARINA, 1993). Entretanto, contrariando o regulamento, foi constatado que muitos abscessos hepáticos únicos levaram à condenação total do fígado pelo inspetor, ocasionando perdas econômicas importantes. Para diminuí-las, sugere-se a condenação parcial de órgãos com abscessos únicos já encapsulados, conforme indica o regulamento, pois nesses não se observou comprometimento histológico das partes não afetadas e distantes do foco abscedativo.

Das amostras do G1, 16,1\% apresentaram lesão característica de fasciolose. Este achado está bem acima dos citados por ROBERTS (1982), entre 0,4 e $5,4 \%$, e por UENO et al. (1982), em 2\%; mas próximo dos dados de MELLO (2000), 20,5\%. Vale lembrar que os valores acerca desta parasitose variam devido às condições de manejo e região de criação. Na figura $1 \mathrm{C}$ e D, observam-se espessamento de ductos biliares e fibrose focalmente extensa do parênquima hepático, em fígados com fasciolose.

Dos fígados condenados por fasciolose, 82\% eram provenientes de animais criados na forma de semiconfinamento, geralmente nos últimos meses antes do abate, e $15 \%$ de animais criados exclusivamente em pastagem natural e/ou cultivada. Acredita-se que esses números se devem à introdução de animais portadores de parasitas, que contaminam com fezes e ovos os locais de acesso à água ou aos alimentos, proliferando, assim, a fasciolose em caso da presença do hospedeiro intermediário. Sabe-se que uma única Fasciola sp. pode sobreviver até onze anos alojada no interior do parênquima hepático, e os ovos podem contaminar outro animal em apenas nove dias, em condições favoráveis (KELLY, 1993). Portanto, aconselha-se a utilização de um antiparasitário específico para a fasciolose, eficaz tanto para os adultos como para as formas jovens do parasito poucos dias antes de introduzir esses animais na propriedade, em um espaço restrito e/ou pequeno.

No grupo 1 , somente em $2,4 \%$ das amostras coletadas foi observada a presença de infiltrado inflamatório. Estes foram condenados macroscopicamente por evidências leves de fasciolose, mas estas não puderam ser associadas a outras observações microscópicas que comprovassem a ocorrência de hepatite parasitária. No grupo dos órgãos liberados (G2), 12,6\% apresentaram infiltrados inflamatórios. Destes, $86 \%$ foram representados por células mononucleares (MN), em diferentes graus, o restante, por infiltrado misto, células polimorfonucleares (PMN) ou para uma combinação de eosinófilos e células MN, sendo 4,6\% de cada um. A maior parte deste total foi de infiltrados em grau leve e distribuição multifocal (76\%). Para a quantificação destes, os infiltrados inflamatórios em graus discretos foram considerados normais, sendo então computados nestas freqüências somente os em graus leves, moderado e severo.

A fibrose capsular foi causa de condenação em $13,2 \%$ das amostras. Dessas, $69 \%$ foram condenadas por fibrose focal na macroscopia e $68 \%$ não apresentaram reação inflamatória na microscopia; o restante por fibrose multifocal (12\%) e extensa (19\%). Das amostras que apresentaram concomitantemente fibrose capsular e infiltrado inflamatório (32\%), somente um caso (5\%) era composto por células PMN. Isto denota que o processo é bastante crônico em quase todos os casos.

O artigo 169 do Decreto-lei Estadual regulamenta que órgãos com aderência devem ser condenados (SANTA CATARINA, 1993). Ocorreram dez casos de fígados condenados por aderência do diafragma no G1. Todos eles foram representados na microscopia por fibrose da cápsula hepática e em somente $20 \%$ destes havia a presença de infiltrado inflamatório MN leve. Portanto, esses poderiam ser destinados ao consumo humano após a retirada do fragmento de diafragma aderido (toalete), já que não representam nenhum processo infeccioso ativo.

No G1, a ocorrência de necrose microscópica foi de $8,4 \%$, sendo $79 \%$ com distribuição aleatória multifocal em graus leve ou moderado e apenas 7\% não apresentando infiltrado inflamatório 

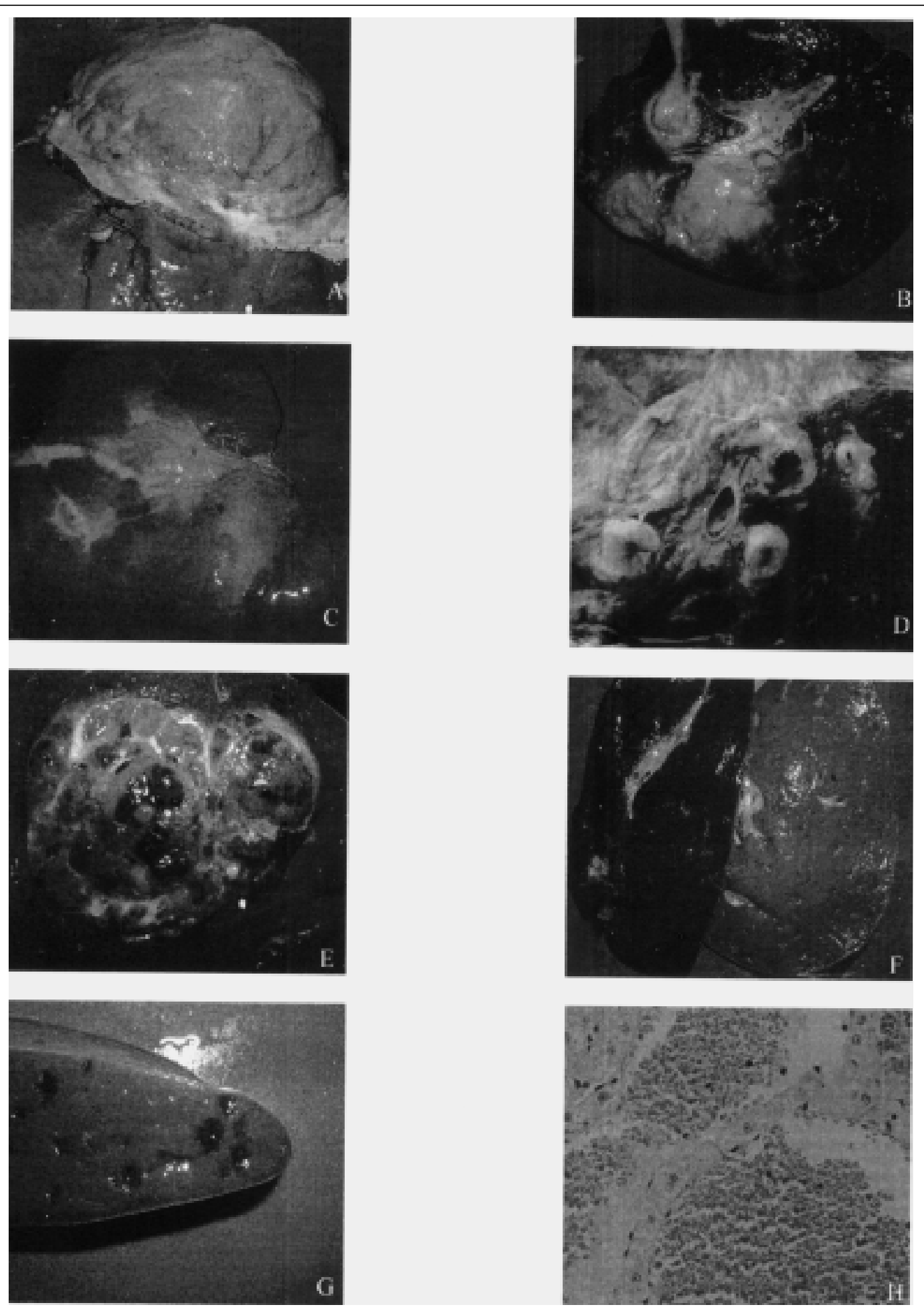

Figura 1 - Lesões encontradas no fígado de bovinos do G1 deste estudo. A) Abscesso único de $18 \mathrm{~cm}$ de diâmetro; B) Abscessos múltiplos de 5 a 8 centímetros de diâmetro; C) Fibrose acentuada focalmente extensa com colapso do parênquima e espessamento de ductos biliares (fasciolose); D) Espessamento de ductos biliares (fasciolose); E) Nódulo com superfície de corte lobulada, de coloração amarelada e com áreas hemorrágicas (adenoma hepatocelular); F) Comparação entre dois fígados, o da esquerda com coloração normal e o da direita amarelado devido à degeneração gordurosa; G) Marcada telangiectasia, superfície de corte; H) Telangiectasia focal leve (aspecto histológico), Obj. 40x. 
associado. Em alguns casos, estes órgãos foram condenados por apresentarem pontos múltiplos de coloração clara. Já no grupo dos órgãos liberados pelo SIE (G2), a ocorrência de necrose foi de 7,8\%, valor muito próximo ao G1, e com características semelhantes às descritas anteriormente.

Foram diagnosticadas três neoplasias, perfazendo $1,8 \%$ das condenações do G1. Foi encontrado um adenoma hepatocelular (Figura 1E), no qual o fígado foi condenado por apresentar telangiectasia acentuada difusa, porém, ao corte do órgão, observou-se a presença do nódulo neoplásico no interior do parênquima, de coloração amarelada, lobulado, consistência firme e medindo aproximadamente 10 x 8cm de tamanho, correspondendo à descrição feita por CULLEN \& POPP (2002). As outras duas neoplasmas eram metástases de carcinomas epidermóides, pois o fígado é o local mais freqüente para a ocorrência dessas metástases, estando atrás somente dos linfonodos regionais da neoplasia primária e do pulmão (CULLEN \& POPP, 2002). Uma amostra foi condenada pela presença de cistos de 1 a 4 centímetros e manchas amareladas e a outra por uma mancha avermelhada na superfície do órgão.

Das amostras do G1, 3,6\% foram condenadas macroscopicamente por coloração amarelada do fígado (Figura 1F) e, algumas vezes, por consistência mais friável. Essas foram erroneamente condenadas por icterícia hepática pelo inspetor. Os órgãos foram representados na microscopia como apresentando degeneração vacuolar bem delimitada do citoplasma de hepatócitos, em graus variáveis, do leve ao acentuado.

As condenações por telangiectasia microscópica no G1 representaram 25,7\% do total. Estes dados estão bem acima dos encontrado por ROBERTS (1982), que variavam de 1,0\% a 8,4\%, mas bem abaixo dos relatados por MELLO (2000), que variavam entre $40,0 \%$ e 42,2\%. Na figura $1 \mathrm{G}$, observa-se a superfície de corte de um fígado condenado por apresentar telangiectasia multifocal leve. Vê-se, na figura $1 \mathrm{H}$, telangiectasia focal leve com formação de lagos de sangue e cordões de hepatócitos isolados, como cita MARCATO et al. (1998).

No grupo 2, foram observados 4,8\% das amostras com telangiectasia microscópica. Em todos os casos, esta alteração estava localizada profundamente e só foi observada após o corte para processamento do material. É importante ressaltar que os casos não foram diagnosticados pelo inspetor. Destas amostras, a maioria (75\%) não apresentava nenhum tipo de infiltrado inflamatório, e os $25 \%$ restantes apresentavam infiltrado MN leve.
Telangiectasia é uma das principais causas de condenação de fígados bovinos pela inspeção (ROBERTS, 1982; MELLO, 2000). Trata-se de uma dilatação dos capilares sinusóides com posterior desaparecimento dos hepatócitos. Ocorre normalmente sem sinais clínicos (KELLY, 1993), sendo o fígado condenado por aspecto repugnante. Conforme o artigo 173 do regulamento de inspeção catarinense, os órgãos afetados por telangiectasia em mais da metade do órgão devem ser condenados totalmente ou, em casos de lesões discretas, destinados ao aproveitamento condicional, após a remoção e condenação da parte afetada (SANTA CATARINA, 1993). Contudo, como a maioria desses órgãos não apresentou células inflamatórias nem algum outro processo patológico, poderiam ser destinados ao consumo humano. Por isso, sugere-se que somente os órgãos com grau acentuado de telangiectasia sejam condenados. Aqueles que apresentam poucos focos poderiam ser liberados ao consumo, contrariando as observações de STOLAND et al. (2001), mesmo porque, em alguns fígados liberados, esses focos não eram visíveis na superfície, mas foram vistos no interior do parênquima hepático.

\section{CONCLUSÕES}

A telangiectasia foi a lesão mais freqüentemente encontrada nos fígados do Grupo 1, tanto macroscópica (32,3\%) como microscopicamente (25,7\%). Em segundo lugar, foram observadas a presença de abscessos e fasciolose em níveis semelhantes, como causa de condenação.

A ocorrência de lesões inflamatórias no Grupo 2 (12,6\%) indica erros no julgamento na linha de abate em decorrência do exame superficial do órgão, demonstrando a necessidade de revisão dos métodos de julgamento praticados pelo SIE.

A denominação incorreta de lesões no G1, como por exemplo, "icterícia hepática”, no caso de fígados amarelados (degeneração gordurosa), pode levar ao armazenamento de dados errados que induzam a conclusões ou diagnósticos falsos.

Há a necessidade de uma readequação no regulamento de inspeção, pois fígados com aderência ao diafragma não apresentaram reação inflamatória aguda, podendo ser destinadas ao consumo. Em certos casos, o inspetor age com demasiado rigor condenando totalmente o órgão, levando a perdas econômicas, quando poderia condená-lo parcialmente, como na presença de um abscesso único. 


\section{AGRADECIMENTOS E APRESENTAÇÃO}

Aos colegas do Sistema de Inspeção Estadual (SIE), pelo valioso auxílio na execução da pesquisa, assim como às empresas que se dispuseram a fornecer material e espaço físico.

Parte da dissertação de mestrado do primeiro autor, apresentada ao programa de Pós-graduação em Ciências Veterinárias, área de concentração em Patologia Animal, Centro de Ciências Agroveterinárias (CAV), da Universidade do Estado de Santa Catarina (UDESC).

\section{COMITÊDEÉTICAEBIOSSEGURANÇA}

Projeto de pesquisa aprovado pelo Comitê de Ética em Experimentação Animal - CETEA - da Universidade do Estado de Santa Catarina, sob protocolo número 1.15/04.

\section{REFERÊNCIAS}

ALBERTON, G.C. Estudo anatomopatológico, microbiológico, citológico e físico das articulações com artrite no abatedouro. 2000. 81f. Tese (Doutorado em Medicina Veterinária) - Faculdade de Medicina Veterinária e Zootecnia, Universidade Estadual Paulista, Botucatu.

BRINK, D.R. et al. Severity of liver abscesses and efficiency of feed utilization of feedlot cattle. J Anim Sci, v.23, p.12011207, 1990 .

CULLEN, J.M.; POPP, J.A. Tumors of the liver and Gall bladder. In: MEUTEN, D.J. (ed). Tumors. 4.ed. Iowa, USA: Iowa State, 2002. p.483-508.

FREITAS, M.R. Caracterização anatomopatológica de bursites cervicais de bovinos abatidos sob Inspeção Federal no estado de Goiás. 1999. 65f. Dissertação (Mestrado em Ciência Animal) - Escola de Veterinária da Universidade Federal de Goiás, Goiânia.

HERENDA, D. et al. Manual on meat inspection for developing countries. Roma, Itália: Food and Agriculture Organization of the United Nations, 1994. 357p.

KELLY, W.R. The liver and biliary system. In: JUBB, K. et al. Pathology of domestic animals. 4.ed. New York, USA: Academic, 1993. p.319-406.

MARCATO, P.S. et al. Preteleangiectasis and telangiectasis of the bovine liver: a morphological, immunohistochemical and ultrastructural study. J Comp Pathology, v.119, p.95-110, 1998.

MELLO, F.A.M. Ocorrência de condenações de órgãos comestíveis de bovinos em estabelecimentos de abate sob diferentes regimes de inspeção no Estado do Rio de Janeiro. 2000. 53f. Trabalho de Conclusão de Curso. (Graduação em Medicina Veterinária) - Universidade do Grande Rio.

MENDENHALL, W.; BEAVER, R.J. Introduction to probability and statistics. 8.ed. Boston, USA: PWS-Kent, 1990. p.237-280.

MOREIRA, F.B.E.C. et al. Causas de condenações de fígados bovinos em frigoríficos de Minas Gerais e perdas econômicas associadas. Rev Hig Alimentar, v.62, n.13, p.22-27, 1999.

NAGARAJA, T.G. et al. Bacterial flora of liver abscesses in feedlot cattle fed tylosin or no tylosin. J Anim Sci, v.77, n.4, p.973-978, 1999.

NEVES D.S. Patologia renal de suínos abatidos para consumo. 1985. 69f. Dissertação (Mestrado em Medicina Veterinária) - Escola de Veterinária da Universidade de Minas Gerais, Belo Horizonte.

O'SULLIVAN, E.N. Two-year study of bovine hepatic abscessation in 10 abattoirs in County Cork, Ireland. Vet Rec, v.145, n.14, p.389-393, 1999.

ROBERTS, J.L. The prevalence and economic significance of liver disorders and contamination in grain-fed and grass-fed cattle. Aust Vet J, v.59, n.5, p.129-132, 1982.

ROSEMBERGER, G.; STRÖBER, M. Malattie del fegato e delle vie biliari. In: ROSEMBERGER, G. Malattie del bovino. Piacenza, Itália: Essegivi, 1970. p.363-377.

SAMPAIO, I.B.M. Estatística aplicada à experimentação animal. 5.ed. Belo Horizonte: Fundação de Ensino e Pesquisa em Medicina Veterinária e Zootecnia, 2002. 256p.

SANTA CATARINA. Decreto-Lei $\mathrm{n}^{\circ}$ 3.748, de 12 de julho de 1993. Regulamento da Inspeção Industrial e Sanitária de Produtos de Origem Animal. Diário Oficial [do] Estado de Santa Catarina, Florianópolis, 28 jul. 1993.

SANTOS, J.A. Patologia especial dos animais domésticos (mamíferos e aves). Rio de Janeiro: Guanabara, 1986. 576p.

STOTLAND, E.I. et al. Bacterial microflora of normal and telangiectatic livers in cattle. J Am Vet Med Assoc, v.19, n.1, p.36-39, 2001.

UENO, H. et al. Fascioliasis problems in ruminants in Rio Grande do Sul, Brazil. Vet Parasitology, v.11, p.185-191, 1982.

WILSON, A. Inspeccion pratica de la carne. Zaragoza, Espanha: Acribia, 1970. 203p. 